\title{
Not All Tumors Evaluated
}

National Cancer Institute

\section{Source}

National Cancer Institute. Not All Tumors Evaluated. NCI Thesaurus. Code C103424.

Not all target tumors or non-target tumors were assessed. 